\title{
A Study on Perceived Weight, Eating Habits, and Unhealthy Weight Control Behavior in Korean Adolescents
}

This study compared actual weight with perceived weight, described the prevalence of unhealthy weight control behavior, determined the differences in psychological and personal variables between participants that reported unhealthy weight control behavior and those who did not, and examined the relationship of eating habits to unhealthy weight control behavior for Korean adolescents. The study population consisted of a nationally representative sample of middle and high school students who completed the Fifth Korea Youth Risk Behavior Web-based Survey (KYRBWS): Fifth in 2009. Among the 75,066 participants of KYRBWS, 35,473 ( $n=18,851$ girls and 16,622 boys) were eligible for a research focused on unhealthy weight control behavior. The results of this research were as follows: First, there were considerable discrepancies (45.1\% of girls and 32.8\% of boys) between the perceived weight and the actual weight. Second, overall, unhealthy weight control behavior was more prevalent in girls and fasting was the most commonly reported behavior. Third, participants that reported unhealthy weight control behavior scored significantly lower on scaled measures of happiness, health, academic achievement, and economic status; in addition, they scored higher on stress measures. Fourth, girls and boys shared common protective factors of having breakfast and vegetables more often, perceiving their weight as underweight rather than overweight, and having a correct weight conception. Protective factors unique to girls were having lunch and dinner more often.

\footnotetext{
Post-doctoral Research Fellow, Dept. of Educational Psychology and Learning Systems, Florida State University, US (nansooksb@gmail.com)

Key Words: unhealthy weight control behavior (UWCB), eating habits, actual weight, perceived weight, Body Mass Index (BMI), adolescent, Korea Youth Risk Behavior Web-based Survey (KYRBWS)
}

Girls and boys shared common risk factors of the consumption of soda, fast food, instant noodles, and snacks more often, while consumption of fruit more often was a risk factor only for girls. The improvement of protective factors and minimization of risk factors through Home Economics classes (and other classes relevant to health) may mitigate unhealthy weight control behavior of adolescents.

\section{INTRODUCTION}

\section{Purpose of Research}

Adolescence is a critical period of life characterized by physical and psychological changes. Dynamic body changes may affect body image perception in adolescence. Body image perception consists of two important dimensions such as body weight perception and attitudes towards personal physique (Xie et al., 2003). Boys chose 'health' as the primary reason for weight control (Chung \& Lee, 2010; Kang, 2005; Kim \& Jang, 2009), while the girls selected 'good appearance' (Chung \& Lee, 2010), 'purchase of clothes' (Kang, 2005), and 'enhancement of confidence' (Kim \& Jang, 2009).

Strong correlates of dieting behavior included overweight status, low self-esteem, depression, suicidal ideation, and substance use (Neumark-Sztainer \& Hannan, 2000). Body image perception affects the emotional well-being of adolescents. The more negative the body image, the lower self-esteem they had (Kim \& Jang, 2009; Kim \& Kim, 2009). Adolescents with a self-perception as overweight were more likely to experience anxiety and depression than those with a self-perception as normal and 
underweight (Xie et al., 2003).

Adolescents are likely to be exposed to a high risk of unhealthy weight control behavior (UWCB). Among those who reported having experiences to lose weight, $17.6 \%$ of Korean adolescents experienced unhealthy weight control behavior (Korea Centers for Disease Control and Prevention, 2009), while $30 \%$ of boys and over $55 \%$ of girls reported unhealthy weight control behavior in the US (Croll, Neumark-Sztainer, Story, \& Ireland, 2002). Unhealthy weight control behavior is likely to result in physical growth disorders or eating disorders in adolescents.

The total score of eating habits showed no variation according to weight control attempts (Chung \& Lee, 2010), while there were significant differences in the frequency of meals and food according to weight control attempts (Kang \& Lee, 2006). The discrepancy of the results might be due to the small sample size and the absence of controlled covariates. Many studies have been conducted with small clinical samples or a comparatively small population-sample and it has been difficult to accurately investigate weight-related behavior in adolescents (Croll et al., 2002).

Individual factors associated theoretically and empirically with body weight perception and dieting behavior include a high body mass index (BMI), low emotional well-being, and low self-esteem. The following studies investigated weight-related variables, after controlling for psychological and personal variables: grade, residence, pubertal stage, parents' education levels, family income, and BMI (Xie et al., 2006), personal (self-esteem, emotional well-being, appearance concerns), socio-environmental (parents in the household, family connectedness, school connectedness, and peer support), behavioral characteristics (academic achievement, alcohol use, bingedrinking, and cigarette smoking) (Croll et al., 2002), age, living with parents, academic achievement, parents' education levels, economic status, cigarette smoking, alcohol use, sleeping-pill use, and depression (Kim, Cho, Cho, \& Lim, 2009), self-esteem, depression, and anxiety (Paxton, Schutz, Wertheim, \& Muir, 1999). In this research, national schoolbased data were used for analyses and BMI, health, stress, academic achievement, economic status, depression, suicidal ideation, suicidal attempts, and grades were used as covariates.

The purposes of this study were to: 1) compare actual weight with perceived weight, 2) describe the prevalence of unhealthy weight control behavior, 3) determine the differences in psychological and personal variables between participants reporting unhealthy weight control behavior and those not reporting them, and 4) examine the relationship of eating habits to unhealthy weight control behavior in Korean adolescents that will help identify the risk and protective factors associated with unhealthy weight control behavior. The present research examined these associations in a large national sample of adolescents and will provide resources for youth with unhealthy weight control behavior.

\section{Research Questions}

1. How much agreement is there between actual weight and perceived weight?

2. What is the prevalence of unhealthy weight control behavior?

3. Do scaled variable scores (happiness, health, stress, academic achievement, and economic status) differ between participants that report overall and individual unhealthy weight control behavior and those that do not?

4. Do eating habits, physical activity, perceived weight, and weight conception have significant associations with unhealthy weight control behavior after personal, physical, and psychological variables are considered?

\section{METHOD}

\section{Data and Participants}

Data for this study were drawn from the Fifth Korea Youth Risk Behavior Web-based Survey (KYRBWS) in 2009. The KYRBWS has been conducted by the Korea Centers for Disease Control and Prevention (KCDC) and the Ministry of Health and Welfare of Korea in cooperation with the Ministry of Education, Science, and Technology of Korea since 2005 to monitor youth health-related behavior. The participants were selected by a stratified random 
cluster sampling of students from 400 middle and 400 high schools based on the proportions of students located in each area. The participants voluntarily completed the anonymous, selfadministered web-based survey during class hours after the completion of consent forms from the students and parents. The survey consisted of 129 questions to assess youth health-related behavior. The overall response rate was $97.6 \%(75,066 / 76,937)$. Information on personal identity was removed by KCDC before the data set was released for public use.

This study focused on the relationship of eating habits and other variables to unhealthy weight control behavior after controlling for BMI, health, stress, academic achievement, economic status, depression, suicidal ideation, suicidal attempts, and grades. A total of 39,593 individuals who, did not report their weight and height for BMI calculation (2,667 participants) and did not answer the dichotomous items for unhealthy weight control behavior (36,926 participants), were excluded. This study included 35,473 cases (18,851 girls and 16,622 boys) out of 75,066 participants.

\section{Measures}

Variables used in these analyses were weight, height, perceived weight, unhealthy weight control behavior, health, stress, academic achievement, economic status, depression, suicidal ideation, suicidal attempts, grades, frequencies of meals (breakfast, lunch, and dinner), frequencies of foods (fruit, soda, fast food, instant noodles, snacks, vegetables, and milk), and frequency of physical activity derived from the Fifth KYRBWS.

Actual weight BMI is defined as weight in kilograms divided by the square of the height in meters $\left(\mathrm{kg} / \mathrm{m}^{2}\right)$ (WHO, 2000). In this study, BMI was calculated based on self-reported weight and height. Actual weight was classified by a BMI cut-off for Asian people: underweight $(\mathrm{BMI}<18.5)$, normal weight $(18.5 \leq \mathrm{BMI}<23)$, and overweight (or obese) $(\mathrm{BMI} \geq 23)$ (WHO, 2000).

Perceived weight To measure the self-perceived weight, respondents were asked to answer the following survey question with a 5-point scale: "Do you consider yourself now to be very underweight, slightly underweight, about right, slightly overweight, and very overweight?" Perceived weight was also classified into 3 groups to match the ways to categorize actual weight: underweight (very underweight and slightly underweight), normal weight (about right), and overweight (slightly overweight and very overweight).

Weight conception Weight conception was classified by a comparison of actual weight with perceived weight. Participants who correctly estimated their body weight were classified as 'correct conception'. Participants who perceived themselves as relatively underweight and who were not actually underweight were classified as 'misconception of underweight.' Participants who perceived themselves as relatively overweight and who were not actually overweight were classified as 'misconception of overweight'. Participants who considered their body about right but were actually either underweight or overweight were classified as 'misconception of normal weight'. These four categories were collapsed into two categories of 'correct conception' and 'misconception'.

Unhealthy weight control behavior (UWCB) With regard to unhealthy weight control behavior, the participants were asked, "Have you used the following methods in order to control weight during the past 30 days?: (1) fasting, (2) nonprescription diet pills, (3) laxatives or diuretics, (4) vomiting, and (5) one-food diet" The participants were asked to answer 'yes' or 'no' for each item. Responses to the 5 items related unhealthy weight control behavior were coded into 3 categories: never, use of 1-2 methods, and use of 3-5 methods.

Psychological and personal measures To measure happiness, health, stress, academic achievement, and economic status, the participants were asked to rate the extent to which they agree with each item on a 5point Likert scale that ranged from 1 (very low) to 5 (very high). Depression, suicidal ideation, and suicidal attempts have dichotomized conventions. 
Table 1. Descriptive Characteristics of the Participants [n (\%)]

\begin{tabular}{|c|c|c|c|c|}
\hline \multicolumn{2}{|l|}{ Variable } & $\begin{array}{c}\text { Girls } \\
(n=18,851)\end{array}$ & $\begin{array}{c}\text { Boys } \\
(n=16,622)\end{array}$ & $\begin{array}{c}\text { Total } \\
(n=35,473)\end{array}$ \\
\hline \multirow[t]{3}{*}{$\overline{\mathrm{UWCB}}$} & Never & $15,297(81.1)$ & $14,930(89.8)$ & $30,227(85.2)$ \\
\hline & Use of 1-2 Methods & $3,147(16.7)$ & $1,395(8.4)$ & $4,542(12.8)$ \\
\hline & Use of 3-5 Methods & $407(2.2)$ & $297(1.8)$ & $704(2.0)$ \\
\hline \multicolumn{2}{|l|}{$\overline{\mathrm{BMI}}($ mean [SD]) } & $20.53[2.53]$ & $21.49[3.41]$ & $20.98[3.01]$ \\
\hline \multicolumn{2}{|l|}{ Health } & $3.67[0.83]$ & $3.87[0.84]$ & $3.76[0.84]$ \\
\hline \multirow{2}{*}{\multicolumn{2}{|c|}{$\begin{array}{ll}\text { Stress } & \text { 5-Point Scale } \\
\text { Academic Achievement } & \text { (mean [SD]) }\end{array}$}} & $3.56[0.92]$ & $3.26[0.95]$ & $3.42[0.94]$ \\
\hline & & $2.90[1.17]$ & $2.96[1.20]$ & $2.93[1.19]$ \\
\hline \multicolumn{2}{|c|}{ Economic Status } & $2.95[0.90]$ & $3.10[0.10]$ & $3.02[0.95]$ \\
\hline \multirow[t]{2}{*}{ Depression } & No & $10,139(53.8)$ & $10,874(65.4)$ & $21,013(59.2)$ \\
\hline & Yes & $8,712(46.2)$ & $5,748(34.6)$ & $14,460(40.8)$ \\
\hline \multirow{2}{*}{ Suicidal Ideation } & No & $13,977(74.1)$ & $13,860(83.4)$ & $27,837(78.5)$ \\
\hline & Yes & $4,874(25.9)$ & $2,762(16.6)$ & $7,636(21.5)$ \\
\hline \multirow{2}{*}{$\begin{array}{l}\text { Suicidal Attempts } \\
(n=7,636)\end{array}$} & No & $3,520(18.7)$ & $2,082(12.5)$ & $5,602(15.8)$ \\
\hline & Yes & $1,354(7.2)$ & $680(4.1)$ & $2,034(5.7)$ \\
\hline \multirow{2}{*}{ Dwelling } & With Family & $18,189(92.7)$ & $16,917(96.9)$ & $35,106(94.7)$ \\
\hline & Others & $1,435(7.3)$ & $538(3.1)$ & $1,973(5.3)$ \\
\hline \multirow{3}{*}{$\begin{array}{l}\text { Educational Attainment } \\
\text { of Father }\end{array}$} & Below High School & $1,410(8.4)$ & $1,139(8.0)$ & $2,549(8.2)$ \\
\hline & High School & $7,852(47.0)$ & $6,255(43.8)$ & $14,107(45.5)$ \\
\hline & College & $7,438(44.5)$ & $6,880(48.2)$ & $14,318(46.2)$ \\
\hline \multirow{3}{*}{$\begin{array}{l}\text { Educational Attainment } \\
\text { of Mother }\end{array}$} & Below High School & $1,405(8.3)$ & $1,063(7.6)$ & $2,468(8.0)$ \\
\hline & High School & $10,169(60.3)$ & $7,780(55.7)$ & $17,949(58.2)$ \\
\hline & College & $5,292(31.4)$ & $5,131(36.7)$ & $10,423(33.8)$ \\
\hline \multirow[t]{6}{*}{ Grade } & $7^{\text {th }}$ & $3,068(16.3)$ & $3,154(19.0)$ & $6,222(17.5)$ \\
\hline & $8^{\text {th }}$ & $3,244(17.2)$ & $2,979(17.9)$ & $6,223(17.5)$ \\
\hline & $9^{\text {th }}$ & $3,360(17.8)$ & $2,914(17.5)$ & $6,274(17.7)$ \\
\hline & $10^{\text {th }}$ & $3,175(16.8)$ & $2,864(17.2)$ & $6,039(17.0)$ \\
\hline & $11^{\text {th }}$ & $3,476(18.4)$ & $2,670(16.1)$ & $6,146(17.3)$ \\
\hline & $12^{\text {th }}$ & $2,528(13.4)$ & $2,041(12.3)$ & $4,569(12.9)$ \\
\hline \multicolumn{5}{|l|}{ Frequency of Meals } \\
\hline \multirow[t]{2}{*}{ Breakfast } & $<=2$ Days a Week & 4,921 (26.1) & 4,645 (27.9) & $9,566(27.0)$ \\
\hline & >3 Days a Week & $13,930(73.9)$ & $11,977(72.1)$ & $25,907(73.0)$ \\
\hline \multirow{2}{*}{ Lunch } & $<=2$ Days a Week & $1,569(8.3)$ & $2,322(14.0)$ & $3,891(11.0)$ \\
\hline & >3 Days a Week & $17,282(91.7)$ & $14,300(86.0)$ & $31,582(89.0)$ \\
\hline \multirow[t]{2}{*}{ Dinner } & $<=2$ Days a Week & $2,307(12.2)$ & $2,375(14.3)$ & $4,682(13.2)$ \\
\hline & >3 Days a Week & $16,544(87.8)$ & $14,247(85.7)$ & $30,791(86.8)$ \\
\hline \multicolumn{5}{|c|}{ Frequency of Eating Foods } \\
\hline Fruit & $<1$ a Day & $14,041(74.5)$ & $12,472(75.0)$ & $26,513(74.7)$ \\
\hline & $>=1 \mathrm{a}$ Day & $4,810(25.5)$ & $4,150(25.0)$ & $8,960(25.3)$ \\
\hline Soda & $<1$ a Day & $18,112(96.1)$ & $15,431(92.8)$ & $33,543(94.6)$ \\
\hline & $>=1 \mathrm{a}$ Day & $739(3.9)$ & $1,191(7.1)$ & $1,930(5.4)$ \\
\hline Fast Food & $<1$ a Day & $18,502(98.1)$ & $16,140(97.1)$ & $34,642(97.7)$ \\
\hline & $>=1 \mathrm{a}$ Day & $349(1.9)$ & $482(2.9)$ & $831(2.3)$ \\
\hline Instant Noodles & $<1$ a Day & $18,386(97.5)$ & $15,826(95.2)$ & $34,212(96.4)$ \\
\hline & $>=1 \mathrm{a}$ Day & $465(2.5)$ & $796(4.8)$ & $1,261(3.6)$ \\
\hline Snacks & $<1$ a Day & $16,936(89.8)$ & $15,227(91.6)$ & $32,163(90.7)$ \\
\hline & $>=1 \mathrm{a}$ Day & $1,915(10.2)$ & $1,395(8.4)$ & $3,310(9.3)$ \\
\hline Vegetables & $<1$ a Day & $10,754(57.0)$ & $9,163(55.1)$ & $19,917(56.1)$ \\
\hline & $>=1$ a Day & $8,097(43.0)$ & $7,459(44.9)$ & $15,556(43.9)$ \\
\hline Milk & $<1$ a Day & $14,372(76.2)$ & $10,300(62.0)$ & $24,672(69.6)$ \\
\hline & $>=1 \mathrm{a}$ Day & $4,479(23.8)$ & $6,322(38.0)$ & $10,801(30.4)$ \\
\hline Frequency of physical a & activity & & & \\
\hline High level & $<2$ Days a Week & $11,068(58.7)$ & $4,777(28.7)$ & $15,845(44.7)$ \\
\hline & $>=2$ Days a Week & $7,783(41.3)$ & $11,845(71.3)$ & $19,618(55.3)$ \\
\hline & $<2$ Days a Week & $10,385(55.1)$ & $5,614(33.8)$ & $15,999(45.1)$ \\
\hline Medium level & $>=2$ Days a Week & $8,466(44.9)$ & $11,008(66.2)$ & $19,474(54.9)$ \\
\hline & Correct Conception & $10,349(54.9)$ & $11,160(67.1)$ & $21,509(60.6)$ \\
\hline Weight conception & Misconception & $8,502(45.1)$ & $5,462(32.9)$ & $13,964(39.4)$ \\
\hline
\end{tabular}


Depression was assessed by asking, "Have you ever felt sadness or depression for more than 2 weeks during the past 12 months?" Suicidal ideation was assessed by asking, "Have you ever seriously thought of suicide in the past 12 months?" Suicidal attempts were assessed by asking, "Have you ever attempted suicide in the past 12 months?" Respondents could answer 'yes' or 'no' for depression, suicidal ideation, and suicidal attempts.

\section{Statistical Analyses}

Unadjusted associations between perceived weight and actual weight were compared by cross-tabulation and kappa statistics of agreement. Descriptive statistics (mean, standard deviation, and percentage) were calculated to reflect the characteristics of the participants. Independent $t$-tests were used to compare the data of scaled variables that include happiness, health, stress, academic achievement, and economic status.

Ordinal regression tested differences in eating habits, physical activities, perceived weight, and weight conception by unhealthy weight control behavior as an ordered, three-category variables (never, use of 1-2 methods, and use of 3-5 methods). The ordinal regression model was stratified by gender. All comments on odds ratio refer to the odds of being in a higher (more), rather than lower, UWCB category, with 'use of 3-5 methods' as the highest (most) category; estimates throughout are followed by $95 \%$ confidence intervals. Statistical analyses were performed by IBM SPSS.

\section{RESULTS}

\section{Characteristics of the Participants}

The characteristics of the participants are presented in Table 1. More girls than boys reported unhealthy weight control behavior. With respect to the scaled measures, the participants placed themselves in slightly higher levels of health and stress, while, they placed themselves in slightly lower levels of academic achievement and economic status. Girls experienced depression, suicidal ideation, and suicidal attempts more often than boys did $(46.2 \%$ versus $34.6 \%$, $25.9 \%$ versus $16.6 \%$, and $7.2 \%$ versus $4.1 \%$, respectively). The majority of participants live with their family at home, while only $5.3 \%$ of the participants live with relatives, in boarding houses, or orphanages. The educational attainment of fathers was higher than that of mothers. Slightly more middle school students than high school students were included in the sample. The levels of grades were evenly distributed between girls and boys. Boys skipped meals slightly more than girls did. The frequencies of consuming, soda, fast food, instant noodles, vegetables, and milk are slightly larger for boys than girls (except fruit and snacks). More boys than girls are involved in physical activities, regardless of the level of physical activity.

\section{Comparison of Actual Weight with Perceived Weight}

Table 2 shows a cross-tabulation of actual weight with the perceived weight for each gender. The majority of girls and boys place themselves as overweight, $49.0 \%$ and $44.7 \%$, respectively. With

Table 2. Comparison of Actual Weight with Perceived Weight [n (\%)]

\begin{tabular}{|c|c|c|c|c|}
\hline \multirow{2}{*}{ Actual Weight } & \multicolumn{4}{|c|}{ Perceived Weight } \\
\hline & Underweight & Normal Weight & Overweight & Total \\
\hline \multicolumn{5}{|l|}{ Girls $(n=18,851)$} \\
\hline $\begin{array}{l}\text { Underweight } \\
\text { Normal Weight } \\
\text { Overweight } \\
\text { Total }\end{array}$ & $\begin{array}{r}2,120(11.2) \\
601(3.2) \\
1(0.0) \\
2,722(14.4)\end{array}$ & $\begin{array}{r}1,554(8.2) \\
5,237(27.8) \\
98(0.5) \\
6,889(36.5)\end{array}$ & $\begin{array}{r}315(1.7) \\
5,933(31.5) \\
2,992(15.9) \\
9,240(49.0)\end{array}$ & $\begin{array}{r}3,989(21.2) \\
11,771(62.4) \\
3,091(16.4)\end{array}$ \\
\hline \multicolumn{5}{|l|}{ Boys $(n=16,622)$} \\
\hline $\begin{array}{l}\text { Underweight } \\
\text { Normal Weight } \\
\text { Overweight } \\
\text { Total }\end{array}$ & $\begin{array}{r}2,885(17.4) \\
1,840(11.1) \\
37(0.2) \\
4,762(28.6)\end{array}$ & $\begin{array}{r}514(3.1) \\
3,484(21.0) \\
440(2.6) \\
4,438(26.7)\end{array}$ & $\begin{array}{r}103(0.6) \\
2,528(15.2) \\
4,791(28.8) \\
7,422(44.7)\end{array}$ & $\begin{array}{l}3,502(21.1) \\
7,852(47.2) \\
5,268(31.7)\end{array}$ \\
\hline
\end{tabular}


Table 3. Overall and Individual Unhealthy Weight Control Behavior by Gender [n (\%)]

\begin{tabular}{llrrr}
\hline & Variable & \multicolumn{1}{c}{$\begin{array}{c}\text { Girls } \\
(n=18,851)\end{array}$} & $\begin{array}{c}\text { Boys } \\
(n=16,622)\end{array}$ & $\begin{array}{c}\text { Total } \\
(n=35,473)\end{array}$ \\
\hline Overall Unhealthy Weight Control Behavior & ${ }^{\mathrm{a}}$ & $3,759(19.9)$ & $1,881(11.3)$ & $5,640(15.9)$ \\
\hline & Fasting & $1,953(10.4)$ & $1,112(6.7)$ & $3,065(8.6)$ \\
Individual & Nonprescription diet pills & $513(2.7)$ & $388(2.3)$ & $901(2.5)$ \\
Unhealthy Weight & Laxative or diuretics & $709(3.8)$ & $473(2.8)$ & $1,182(3.3)$ \\
Control Behavior & Vomiting & $935(5.0)$ & $553(3.3)$ & $1,488(4.2)$ \\
& One-food diet & $1,752(9.3)$ & $866(5.2)$ & $2,618(7.4)$ \\
\hline
\end{tabular}

Note. ${ }^{a}$ Overall unhealthy weight control behavior is defined as admitted use of one or more unhealthy weight control behaviors (fasting, nonprescription diet pills, laxative or diuretics, vomiting, and one-food diet) to lose or control weight.

respect to actual weight status, the majority of girls (62.4\%) and boys (47.2\%) had normal weight. For the off-diagonal, $45.1 \%$ of girls and $32.8 \%$ of boys, misclassified their weight status and indicated that girls are more likely to have a misconception of their own weight than boys. In the comparison of actual weight with perceived weight, the majority of girls (31.5\%) perceived themselves as being overweight even though their actual weight is normal, while only $15.2 \%$ of boys were in this respect. The strength of the corresponding agreement was fair in girls $(\mathrm{Kappa}=0.32)$ and moderate in boys (Kappa $=0.51)$. Further analyses to investigate the relationship of perceived weight and the weight conception to unhealthy weight control behavior are needed.

\section{Prevalence of Unhealthy Weight Control Behavior}

The unadjusted prevalence of overall and individual unhealthy weight behavior by gender is shown in Table 3. Overall, unhealthy weight control behavior was more prevalent in girls. It is reasonable because the percentage of girls who perceived themselves as overweight was higher than that of boys. Around $20 \%$ of girls and $11 \%$ of boys reported unhealthy weight control behavior. Looking at individual unhealthy weight control behavior, fasting was the most frequently reported behavior, followed by a one-food diet, vomiting, laxative or diuretics, and nonprescription diet pills, regardless of gender; in addition, fasting or skipping meals was the most commonly reported behavior (Croll et al., 2002).

\section{Scaled Variables and Unhealthy Weight Control Behavior}

The scores for each scaled measure were examined across unhealthy weight control behavior. The following variables were measured by a 5-Likert scale: happiness, health, stress, academic achievement, and economic status. A Kolmogorov-Smirnoff test was used to properly test for normality. The Kolmogorov-Smirnoff test showed that the distributions of all scaled variables were normal and indicated that the data set was fit to a $t$-test. Table 4 presents the results of mean difference tests of scaled variable scores (happiness, health, stress, academic achievement, and economic status) between participants that reported overall and individual unhealthy weight control behavior and those that did not, this indicates that almost all mean differences are statistically significant. However, significant differences in academic achievement and economic status were not observed between participants that reported nonprescription diet pills and laxative or diuretics and their counterparts that did not. Participants that reported unhealthy weight control behavior scored significantly lower on scaled measures of happiness, health, academic achievement, and economic status; in addition, they scored higher on stress measures.

\section{Risk and Protective Factors Associated with Unhealthy Weight Control Behavior.}

Ordinal regression was generated to compare eating habits, physical activity, perceived weight, and weight conception among UWCB categories after adjustment for BMI, health, stress, academic achievement, economic status, depression, suicidal ideation, suicidal attempts, and grades to determine risk and protective factors. Table 5 shows the results of ordinal regression with unhealthy weight control behavior as an ordered three-category variable. 
Table 4. Mean Difference Tests of Scaled Variable Scores across Overall and Individual Unhealthy Weight Control Behavior

\begin{tabular}{|c|c|c|c|c|c|c|c|}
\hline \multirow[b]{2}{*}{ Variables $^{\mathrm{a}}$} & & \multirow{2}{*}{$\begin{array}{c}\text { Overall } \\
\text { Unhealthy } \\
\text { Weight Control } \\
\text { Behavior }\end{array}$} & \multicolumn{5}{|c|}{ Individual unhealthy weight control behavior } \\
\hline & & & Fasting & $\begin{array}{l}\text { Nonpres-cription } \\
\text { Diet Pills }\end{array}$ & $\begin{array}{l}\text { Laxative or } \\
\text { Diuretics }\end{array}$ & Vomiting & One-food Diet \\
\hline \multirow{3}{*}{ Happiness } & No & 3.59 & 3.57 & 3.55 & 3.55 & 3.55 & 3.56 \\
\hline & Yes & 3.30 & 3.26 & 3.44 & 3.42 & 3.28 & 3.38 \\
\hline & $t$ & $19.05^{* * *}$ & $15.12^{* * *}$ & $2.92^{* *}$ & $4.10^{* * *}$ & $9.50^{* * *}$ & $8.41^{* * *}$ \\
\hline \multirow{3}{*}{ Health } & No & 3.79 & 3.77 & 3.76 & 3.76 & 3.77 & 3.77 \\
\hline & Yes & 3.59 & 3.57 & 3.68 & 3.61 & 3.52 & 3.66 \\
\hline & $t$ & $15.41^{* * *}$ & $11.65^{* * *}$ & $2.43^{*}$ & $5.16^{* * *}$ & $9.63^{* * *}$ & $5.74^{* * *}$ \\
\hline \multirow{3}{*}{ Stress } & No & 3.37 & 3.39 & 3.42 & 3.42 & 3.41 & 3.40 \\
\hline & Yes & 3.73 & 3.77 & 3.50 & 3.58 & 3.69 & 3.65 \\
\hline & $t$ & $-25.77^{* * *}$ & $-20.00^{* * *}$ & $-2.30^{*}$ & $-5.07^{* * * *}$ & $-10.18^{* * *}$ & $-12.12^{* * *}$ \\
\hline \multirow{3}{*}{$\begin{array}{l}\text { Academic } \\
\text { Achievement }\end{array}$} & No & 2.97 & 2.94 & 2.92 & 2.92 & 2.93 & 2.94 \\
\hline & Yes & 2.66 & 2.66 & 2.92 & 2.87 & 2.75 & 2.69 \\
\hline & $t$ & $17.94^{* * *}$ & $12.55^{* * *}$ & -0.07 & 1.26 & $5.37^{* * * *}$ & $10.13^{* * *}$ \\
\hline \multirow{3}{*}{ Economic Status } & No & 3.04 & 3.03 & 3.02 & 3.02 & 3.02 & 3.02 \\
\hline & Yes & 2.91 & 2.90 & 3.01 & 3.01 & 2.94 & 2.96 \\
\hline & $t$ & $8.31^{* * * *}$ & $6.34^{* * *}$ & 0.09 & 0.39 & $2.74^{* *}$ & $2.75^{* *}$ \\
\hline
\end{tabular}

Note. ${ }^{*} p<0.05 ;{ }^{* *} p<0.01 ;{ }^{* * *} p<0.001$.

${ }^{a}$ All variables have possible scores of 1-5.

BMI, health, stress, academic achievement, economic status, depression, suicidal ideation, suicidal attempts, and grades were used as covariates.

Stress, academic achievement, depression, suicidal ideation, and suicidal attempts had a significant relationship with UWCB for both genders. Health, economic status, and grades were significantly associated with UWCB only for girls and the association between UWCB and BMI was significant only for boys. However, UWCB category for both genders was not significantly associated with type of dwelling, educational attainment of father and mother that were used as covariates to examine weight-related variables in the studies of Xie et al. (2006) and Kim et al. (2009). No interactions among variables such as stress, depression, suicidal ideation, and suicidal attempts (that were suspected of interrelationship) were found in the ordinal regression analysis.

A one-unit increase in stress was estimated to increase the odds of being in a higher UWCB category by $21 \%$ and $12 \%$ for girls and boys, respectively. A one-unit increase in academic achievement was estimated to decrease the odds of being in a higher UWCB category by $12 \%$ and $10 \%$ for girls and boys, respectively. Those who answered "no" for the questions on depression, suicidal ideation, and suicidal attempts were estimated to have lower odds of being in a higher UWCB category relative to those who answered "yes" for them in both genders. Only for girls, a one-unit increase in health was estimated to decrease the odds of being in a higher UWCB category by $12 \%$ and a one-unit increase in economic status was estimated to increase the odds of being in a higher UWCB category by $7 \%$. Grade had significant associations, with $7^{\text {th }}, 8^{\text {th }}$, and $9^{\text {th }}$ graders estimated to have lower odds of being in a higher UWCB category relative to $12^{\text {th }}$ graders. These odds were 0.47 times, 0.71 times, and 0.85 times lower, respectively. A one-unit increase in BMI (corresponding to an increase in weight of $3.06 \mathrm{~kg}$ for a boy at 1.75 meters in height) was estimated to increase the odds of being in a higher UWCB category by $5 \%$ for boys.

The frequencies of eating meals were related to unhealthy weight control behavior, despite the adjustment for covariates. Those who have breakfast less than 2 days a week had greater odds of placing themselves in a higher UWCB category compared to those who have breakfast more than 3 days a week (1.62 times greater odds in girls and 1.45 times greater odds in boys). No significant relationship between UWCB and the frequency of eating dinner was found in boys. For girls, however, those who 
Table 5. Variables Associated with Unhealthy Weight Control Behavior (UWCBs)

\begin{tabular}{|c|c|c|c|c|c|}
\hline \multicolumn{2}{|l|}{ Variable } & $\begin{array}{c}\text { Girls } \\
\text { OR }\end{array}$ & $95 \% C I$ & $\begin{array}{c}\text { Boys } \\
\text { OR }\end{array}$ & $95 \% C I$ \\
\hline \multicolumn{2}{|l|}{ BMI } & 1.02 & -0.010 .05 & $1.05^{*}$ & 0.030 .08 \\
\hline \multicolumn{2}{|l|}{ Health } & $0.88^{* * *}$ & $-0.18-0.08$ & 0 & -0.090 .03 \\
\hline \multicolumn{2}{|l|}{ Stress } & $1.21^{* * *}$ & 0.140 .24 & $1.12^{* * *}$ & 0.050 .17 \\
\hline \multicolumn{2}{|c|}{ Academic Achievement } & $0.88^{* * *}$ & $-0.16-0.09$ & $0.90^{* * * *}$ & $-0.15-0.06$ \\
\hline \multicolumn{2}{|c|}{ Economic Status } & $1.07^{* *}$ & 0.020 .11 & 1.04 & -0.020 .09 \\
\hline \multirow[t]{2}{*}{ Depression } & No & $0.65^{*}$ & $-0.52-0.34$ & 0.65 & $-0.55-0.31$ \\
\hline & Yes & 1.00 & - & 1.00 & - \\
\hline \multirow[t]{2}{*}{ Suicidal Ideation } & No & $0.49^{*+*}$ & $-0.85-0.58$ & 0.50 & $-0.89-0.49$ \\
\hline & Yes & 1.00 & - & 1.00 & - \\
\hline \multirow[t]{2}{*}{ Suicidal Attempts } & No & $0.70^{*+1}$ & $-0.50-0.23$ & 0.64 & $-0.67-0.23$ \\
\hline & Yes & 1.00 & - & 1.00 & - \\
\hline \multirow[t]{6}{*}{ Grade } & $7^{\text {th }}$ & $0.47^{\text {stwk }}$ & $-0.91-0.61$ & 0.97 & -0.230 .17 \\
\hline & $8^{\text {th }}$ & $0.71^{* * *}$ & $-0.48-0.20$ & 1.03 & -0.170 .23 \\
\hline & $9^{\text {th }}$ & $0.85^{*}$ & $-0.30-0.03$ & 1.17 & -0.040 .35 \\
\hline & $10^{\text {th }}$ & 0.91 & -0.230 .04 & 1.21 & -0.000 .38 \\
\hline & $11^{\text {th }}$ & 0.99 & -0.140 .12 & 1.08 & -0.110 .27 \\
\hline & 12 th & 1.00 & - & 1.00 & - \\
\hline \multicolumn{6}{|l|}{ Frequency of Meals } \\
\hline \multirow[t]{2}{*}{ Breakfast } & $<=2$ days a week & $1.62^{* * *}$ & 0.390 .57 & $1.45^{* * *}$ & 0.250 .50 \\
\hline & $>3$ days a week & 1.00 & - & 1.00 & - \\
\hline \multirow[t]{2}{*}{ Lunch } & $<=2$ days a week & $1.19^{*}$ & 0.030 .31 & 1.19 & -0.030 .38 \\
\hline & $>3$ days a week & 1.00 & - & 1.00 & - \\
\hline \multirow[t]{2}{*}{ Dinner } & $<=2$ days a week & $1.76^{* * *}$ & 0.450 .68 & 1.17 & -0.050 .36 \\
\hline & $>3$ days a week & 1.00 & - & 1.00 & - \\
\hline \multicolumn{6}{|c|}{ Frequency of Eating Foods } \\
\hline \multirow[t]{2}{*}{ Fruit } & $<1$ a day & $0.88^{* *}$ & $-0.22-0.03$ & 0.89 & -0.240 .01 \\
\hline & $>=1$ a day & 1.00 & - & 1.00 & - \\
\hline \multirow[t]{2}{*}{ Soda } & $<1$ a day & $0.70^{* * *}$ & $-0.54-0.19$ & $0.72^{* * * *}$ & $-0.50-0.15$ \\
\hline & $>=1$ a day & 1.00 & - & 1.00 & - \\
\hline \multirow[t]{2}{*}{ Fast Food } & $<1$ a day & $0.74^{*}$ & $-0.56-0.05$ & $0.60^{* * * *}$ & $-0.76-0.26$ \\
\hline & $>=1$ a day & 1.00 & - & 1.00 & - \\
\hline \multirow[t]{2}{*}{ Instant Noodles } & $<1$ a day & $0.66^{* * *}$ & $-0.64-0.20$ & $0.59^{* * * *}$ & $-0.74-0.32$ \\
\hline & $>=1$ a day & 1.00 & - & 1.00 & - \\
\hline \multirow[t]{2}{*}{ Snacks } & $<1$ a day & $0.81^{* *}$ & $-0.33-0.09$ & $0.83^{*}$ & $-0.37-0.02$ \\
\hline & $>=1$ a day & 1.00 & - & 1.00 & - \\
\hline \multirow[t]{2}{*}{ Vegetables } & $<1$ a day & $1.22^{* * *}$ & 0.110 .28 & $1.17^{* *}$ & 0.040 .26 \\
\hline & $>=1$ a day & 1.00 & - & 1.00 & - \\
\hline Milk & $<1$ a day & 0.99 & -0.100 .09 & 1.06 & -0.060 .17 \\
\hline & $>=1$ a day & 1.00 & - & 1.00 & - \\
\hline Physical Activity & & & & & \\
\hline High Level & $<2$ days a week & 0.93 & -0.160 .02 & 0.99 & -0.140 .12 \\
\hline & $>=2$ days a week & 1.00 & - & 1.00 & - \\
\hline Medium Level & $<2$ days a week & 1.05 & -0.040 .13 & 0.97 & -0.150 .10 \\
\hline Mledium Level & $>=2$ days a week & 1.00 & - & 1.00 & - \\
\hline & underweight & 0.76 & $-0.46-0.08$ & $0.75^{* * 4}$ & $-0.48-0.10$ \\
\hline Perceived Weight & normal weight & 0.97 & -0.170 .10 & 0.98 & -0.170 .13 \\
\hline & overweight & 1.00 & - & 1.00 & - \\
\hline We & Correct conception & $0.87^{* * *}$ & $-0.25-0.04$ & $0.83^{*+4}$ & $-0.30-0.07$ \\
\hline Weight Conception & Misconception & 1.00 & - & 1.00 & - \\
\hline
\end{tabular}

Note. ${ }^{*} p<0.05 ;{ }^{* *} p<0.01 ;{ }^{* * *} p<0.001$.

OR, odds ratio; $95 \% C I, 95 \%$ confidence interval.

The table displays an ordinal regression with unhealthy weight control behavior used. Odds ratios refer to the odds of being in a higher rather than lower UWCB category, with "use of 3-5 methods" as the highest category. 
have dinner less than 2 days a week were 1.76 times more likely to be in a higher UWCB category compared to those who have dinner more than 3 days a week.

The frequencies of consuming soda, fast food, instant noodles, snacks, and vegetables were related to unhealthy weight control behavior in girls and boys. Those who seldom have (less than once a day) soda, fast food, instant noodles, and snacks were estimated to have lower odds of being in a higher UWCB category relative to those who often have them (more than once a day). These odds were: 0.70 times lower for girls and 0.72 times lower for boys in regard to soda, 0.74 times lower for girls and 0.60 times lower for boys in regard to fast food, 0.66 times for girls and 0.59 times for boys in regard to instant noodles, and 0.81 times lower for girls and 83 times lower for boys in regard to snacks. Significant associations of UWCB with the frequencies of meals and snacks are related to the result of Yoon \& Lee (2010). Yoon and Lee (2010) identified that obese adolescent girls consumed a significantly greater number of items for snacks and fewer food items for regular meals compared to non-obese girls (Yoon \& Lee, 2010). Those who seldom have vegetables were more likely to be in a higher UWCB category compared to those who often have vegetables, with an odds ratio of 1.22 for girls and 1.17 for boys. Only for girls, those who seldom have fruit were less likely to be in a higher UWCB category compared to those who often have fruit, with an odds ratio of 0.88 . However, no significance between UWCB and the frequencies of lunch, fruit, and milk was found in both genders.

The frequency of physical activity was not significantly associated with UWCB. Perceived weight and weight conception were significantly associated with UWCB for both genders. Those who perceived themselves as underweight were less likely to be in a higher UWCB category compared to those who perceive themselves as overweight, with an odds ratio of 0.76 for girls and 0.75 for boys. Those who correctly estimated their body weight were less likely to be in a higher UWCB category compared to those who misconceived their body weight, with an odds ratio of 0.87 for girls and 0.83 for boys.
The removal of the covariate control for unhealthy weight control behavior led to different results of eating habits and other variables: an increase in the OR of frequency of eating breakfast to $1.72(\mathrm{CI}=[0.530 .70], p<.001)$ for girls, a decrease in the OR of frequency of having soda to $0.67(\mathrm{CI}=$ $[-0.65-0.30], p<.001)$, and no significant relationship of weight conception.

Girls and boys shared common protective factors associated with UWCB: often having breakfast and vegetables, perceiving their weight as underweight than overweight, and correct weight conception. Protective factor unique to girls were often having lunch and dinner. Girls and boys shared common risk factors: often consuming soda, fast food, instant noodles, and snacks, with girls as a group, showing having fruit often as a risk factor associated with UWCB.

\section{CONCLUSION}

This study compared actual weight with perceived weight, described the prevalence of unhealthy weight control behavior, determined the differences in psychological and personal variables between participants reporting unhealthy weight control behavior and those not reporting them, and examined the relationship of eating habits to unhealthy weight control behavior in Korean adolescents.

\section{Summary}

A sample of individuals who have experienced weight control and answered questions on unhealthy weight control behavior with dichotomized conventions were selected out of KYRBWS participants for this research. The results of this research are as follows.

First, there were considerable discrepancies between perceived weight and actual weight and the discrepancy was more marked in girls. Second, overall, unhealthy weight behavior was more prevalent in girls and fasting was the most commonly reported behavior. The results are related to those of previous studies (Chung \& Lee, 2000; Kim \& Jang, 2009) that identified that girls were 
more interested in weight control than boys were. The discrepancy between the actual weight and the perceived weight was more prevalent in girls, who employed UWCBs more than boys did; in addition, the UWCBs seemed to be motivated by perceived weight rather than actual weight. This point is consistent with other studies (Cheung, Ip, Lam, \& Bibby, 2007; Kim \& Jang, 2009). Third, participants that reported any unhealthy weight control behavior were less likely to be happy and healthy than were those that did not. In addition, significantly lower academic achievement and economic status were found in those with unhealthy weight control behavior. Fourth, skipping meals, more often consuming soda, fast food, instant noodles, and snacks, perceived overweight, and misconception of weight were independently associated with unhealthy weight control behavior, which were revealed as risk factors, even after controlling for BMI, health, stress, academic achievement, economic status, depression, suicidal ideation, suicidal attempts, and grades. The improvement of protective factors and minimization of risk factors through Home Economics classes (and other classes relevant to health) may mitigate unhealthy weight control behavior of adolescents.

\section{Discussion}

This study employed national survey data appropriate to the accurate analyses of unhealthy weight control behavior and investigated unhealthy weight control behavior with covariate controls relevant to weight-related behavior. The results of this study reinforced the benefit of having regular meals and the harm of consuming soda, fast food, instant noodles, and snacks that are topics covered in Home Economic classes on eating habits. As weightrelated concerns increase, the construction of suitable and realistic body perceptions need to be highlighted for intervention programs that ensure the physical and psychological well-being of adolescents.

This study has some limitations with regard to actual weight and perceived weight. First, BMI was calculated by self-reported weight and height instead of anthropometric measures in this study. Even though the KYRBWS data does not provide anthropometric measures, BMI calculation from selfreported weight and height is a limitation of this research. Second, in this research, actual weight was categorized by BMI cut-off for Asian people, which is very simple and commonly used criteria for adolescents in the previous studies (Chung \& Lee, 2010; Kim \& Jang, 2009; Lee \& Kim, 2008; Moon \& Lee, 2009). However, the BMI-for-age chart is more appropriate for an accurate assessment to classify the actual weight of adolescents. Third, the KYRBWS provides a limited assessment of self-perceived weight appropriateness. No information of the reference point was given to each participant for a self-assessment of weight. For example, figural stimuli introduced by Stunkard, Sorensen, and Schulsinger (1983) can be a resource appropriate to internal or external norms of self-assessment for participants. The figural stimuli were used to measure body perception in the previous studies (Kim \& Jang, 2009; Kim \& Kim, 2009). Bulik et al. (2001) identified that the use of figural stimuli are a robust technique to classify individuals as obese or thin in the US.

The following suggestions for future research are presented based on the results and limitations of this research. Future studies on perceived weight should address various means to estimate body weight such as reference point and figural stimuli. This study focused on unhealthy weight control behavior instead of healthy weight control behavior. The exploration of variables related to healthy weight control behavior may be a future research topic to determine resources that promote healthy weight control behavior in adolescents. Further studies also should address the impact of socio-cultural contexts on body perception and weight control behavior in adolescents. Adolescents are likely to be affected by peer clique for their appearance and body image as well. Paxton et al. (1999) examined the relationship of friend and peer-related variables to body image and eating behavior. KYRBWS data was not available for peer-related variables. Therefore, adolescent perceptions of views and actions by friends with respect to eating habits and weight control behavior are a prospective topic for future study. 


\section{REFERENCES}

Bulik, C., Wade, T., Heath, A., Martin, N., Stunkard, A., \& Eaves, L. (2001). Relating body mass index to figural stimuli: population-based normative data for Caucasians. International Journal of Obesity, 25, 15171524.

Chang, V. W., \& Christakis, N. A. (2003). Self-perception of weight appropriateness in the United States. American Journal of Preventive Medicine, 24(4), 332-339.

Cheung, P., Ip, P., Lam, S., \& Bibby, H. (2007). A study on body weight perception and weight control behaviors among adolescents in Hong Kong. Hong Kong Medical Journal, 13(1). 16-21.

Chung, H-K., \& Lee, H-Y. (2010). The concepts of weight control and dietary behavior in high school seniors. Korean Journal of Nutrition, 43(6), 607-619.

Croll, J., Neumark-Sztainer, D., Story, M., \& Ireland, M. (2002). Prevalence and risk and protective factors related to disordered eating behaviors among adolescents: Relationship to gender and ethnicity, Journal of Adolescent Health, 31, 166-175.

Kang, G-J. (2005). The recognition of body shape and the attitude toward weight of high school students. Unpublished Master's thesis, Kangwon National University.

Kang, H. W., \& Lee, S. S. (2006). A study on weight control and dietary life among middle school students: nutrition knowledge, dietary behavior, and food frequency. The Korean Journal of Nutrition, 39(8), 817-831.

Kim, D., Cho, Y., Cho, S., \& Lim, I. (2009). Body weight perception, unhealthy weight control behaviors, and suicidal ideation among Korean adolescents. Journal of School Health, 79(12). 585-592.

Kim, H., \& Jang, H. (2009). Body perception, attitude on weight-control and self-esteem according to the weight group of high school students in Daegu. Journal of Korean Home Economics Education, 21(2), 122.

Kim, J., \& Kim, Y. (2009). Body perception, dietary attitude, and self-esteem in middle school boys and girls. Journal of Korean Home Economics Education, 21(1), 123-139.

Korea Centers for Disease Control and Prevention (2009). Statistics of Korea Youth Risk Behavior Webbased Survey (KYRBWS). Available from http:// yhs.cdc.go.kr.

Lee, K-W., \& Kim, B-R. (2008). Weight control attitude, nutrition knowledge and dietary behavior by weight control attempt of high school female students in Wonju area. Journal of Korean Home Economics Education, 20(4), 91-105.

Moon, S., \& Lee, Y. (2009). Comparison of dietary habits, exercise, recognized body shapes and weight control between obesity and underweight of adolescents. Korean Journal of Human Ecology, 18(6). 1337-1348.

Neumark-Sztainer, D., \& Hannan, P. (2000). Weightrelated behaviors among adolescent girls and boys: results from a national study. Archives of Pediatrics and Adolescent medicine, 154(6), 569-577.

Paxton, S. F., Schutz, H. K., Wertheim, E. H., \& Muir, S. L. (1999). Friendship clique and peer influences on body image concerns, dietary restraint, extreme weight-loss behaviors, and binge eating in adolescent girls. Journal of American Psychology, 108(2), 255266.

Stunkard, A., Sorensen, T., \& Schulsinger, F. (1983). Use of the Danish Adoption Register for the study of obesity and thinness. In S. Kety, L. Roland, R. Sidman, \& S. Matthysse (Eds). The genetics of neurological and psychiatric disorders. New York: Raven Press.

World Health Organization [WHO] (2000). The AsiaPacific perspective: Redefining obesity and its treatment. IASO (International Association for the Study of Obesity). Sydney: Health Communications Australia Pty Limited. Retrieved from August 14, 2011, http://www.wpro.who.int/internet/resources.ashx/ NUT/Redefining+obesity.pdf.

Xie, B., Liu, C., Chou, C-P., Xia, J., Spruijt-Metz, D., Gong, J., Li, Y., Wang, H., \& Johnson, A. (2003). Weight perception and psychological factors in Chinese adolescents. Journal of Adolescent Health, 33, 
202-210.

Xie, B., Chou, C-R., Spruijt-Metz, D., Reynolds, K., Clark, F., Palmer, P. H., Gallaher, P., Sun, P., Guo, Q., \& Johnson, A. (2006). Weight perception, academic performance, and psychological factors in Chinese adolescents. American Journal Health Behavior, 30(2), 115-124.

Yoon, J-S., \& Lee N-J. (2010). Dietary patterns of obese high school girls: snack consumption and energy intake. Nutrition Research and Practice, 4(5), 433437.

Received October 23, 2011

Revised November 24, 2011

Accepted December 12, 2011 